\title{
ENTRE O VER E O SER VISTO NOTAS SOBRE A VISIBILIDADE DO HOMEM E DO ANIMAL NO CINEMA E NA LITERATURA
}

\section{Carolina Anglada de Rezende UFMG/CAPES}

RESUMO: Este artigo pretende estabelecer interseções entre a produção cinematográfica Ex isto, de Cao Guimarães, e a obra literária que a motiva, Catatau, de Paulo Leminski, tendo como eixo a discussão sobre as posições ocupadas pelo homem e pelo animal. A fim de evidenciar as implicações de uma inversão crítica propiciada pela exposição do homem, que é perscrutado, e torna-se, imagem, e do animal, que se posiciona como o detentor do olhar, recorremos ao pensamento de George Didi-Huberman, Giorgio Agamben e Michel Foucault.

PALAVRAS-CHAVE: Sujeito-objeto. Homem-animal. Montagem. Cao Guimarães. Paulo Leminski.

\section{BETWEEN SEEING AND BEING SEEN NOTES ON THE VISIBILITY OF MAN AND ANIMAL IN CINEMA AND LITERATURE}

ABSTRACT: This article aims to establish intersections between the film Ex isto, made by Cao Guimarcês, and the literary work that motivates it, Catatau, by Paulo Leminski, with the discussion of the positions occupied by the man and the animal. In order to emphasize the implications of a critical reversal brought by exposure of man, that is scrutinized and becomes image, and animal, which is positioned as the holder of the looking, we turn to the thought of George Didi-Huberman, Giorgio Agamben and Michel Foucault.

KEYWORDS: Subject-object. Man-animal. Assembly. Cao Guimarães. Paulo Leminski.

Carolina Anglada de Rezende é integrante do Programa de Pós-Graduação da Faculdade de Letras da UFMG. 


\section{ENTRE O VER E O SER VISTO \\ NOTAS SOBRE A VISIBILIDADE DO HOMEM E DO ANIMAL NO CINEMA E NA LITERATURA}

Carolina Anglana de Rezende

I- A FÁBULA

"Ver é uma fábula". O aforismo, emitido originalmente pelo poeta Paulo Leminski, na obra experimental Catatau, publicada na década de 1970, sobrevive como forma aberta, força em propagação na produção audiovisual do diretor contemporâneo Cao Guimarães, cujo conjunto da obra, não por acaso, foi reunida em uma mostra, no ano de 2013 e organizada sob esse mesmo mote, o de que "ver é uma fábula". Se a pertinência do gesto do olhar revela-se evidente no âmbito de uma criação visual, como é o caso do cinema de Cao, que pelo trabalho da câmera estende as imagens, prolongando as cenas, o termo que acompanha o aforismo necessita de uma primeira pausa, para que a expressão, de fato, se amplie. Afinal, o mote não dá nome apenas à mostra, mas reverbera nos diferentes ângulos de um dos mais emblemáticos personagens de sua filmografia, René Descartes, interpretado por João Miguel para Ex isto. ${ }^{1}$

Desse modo, o que viria a ser essa fabulação do ver? Recorramos a uma possível genealogia da fábula, na qual encontraríamos um primeiro momento de emergência do gênero na Antiguidade. Aqui, temos o desenvolvimento de uma forma que, por meio da participação de animais nas narrativas, enfatiza o caráter moralizante da história. No entanto, é preciso ressaltar como desde esse momento até o Renascimento a diferenciação hoje tão imediata e axiomática entre observação fábula, imaginação e documento, resvalava em um sistema de pensamento estranho ao moderno. $\mathrm{O}$ curso da história que acabou por cindir definitivamente a fantasia e o conhecimento delata os processos de formação da ciência moderna e as decorrentes fragmentações necessárias para a sustentação de certas teses, como a da distinta

${ }^{1}$ GUIMARÃES, Cao. Ex isto. Minas Gerais: produção independente, 2010. 
racionalidade humana pautada no cogito cartesiano. O filósofo francês Michel Foucault, em seus incessantes empreendimentos arqueológicos, precisamente naquele que resultou em As palavras e as coisas, detém-se sobremaneira no desenrolar dos códigos das ciências humanas tendo em vista a delimitação de uma episteme moderna. Antes de alcançá-la, no entanto, Foucault ocupa-se do que foi a episteme até o século XVI, cercando-a pelos quatro parâmetros ${ }^{2}$ que postulavam a semelhança como modo de entendimento e conhecimento do mundo. Somam-se a esse conjunto de operadores do saber, a magia e a erudição:

Afigura-se-nos que os conhecimentos do século XVI eram constituídos por uma mistura instável de saber racional, de noções derivadas das práticas da magia e de toda uma herança cultural, cujos poderes de autoridade a redescoberta de textos antigos havia multiplicado. [...] De fato, não é de uma insuficiência de estrutura que sofre o saber do século XVI. [...] É esse rigor que impõe a relação com a magia e com a erudição - não conteúdos aceitos, mas formas adquiridas. ${ }^{3}$

Retomar o contexto epistemológico da Antiguidade e da Idade Média revela-se fulcral não apenas por tratar do ambiente no qual o gênero fabular se desenrolou, mas por noções arcaicas que se escondem num modo de pensar e habitar o mundo.

Fundamentando a tese de um outro ponto de vista, o pensador italiano Giorgio Agamben, leitor confesso de Foucault, dá prosseguimento ao método arqueológico foucaultiano, na obra Infância e história, embasando o pensamento benjaminiano de "pobreza de experiência" ${ }^{4}$ nas diversas cisões acarretadas pela formação de uma ciência moderna no século XVII e das consequentes modernizações posteriores. Com vistas na fundamentação do cogito cartesiano e na formação da ideia moderna de "sujeito do conhecimento", Agamben demonstra como se fraturaram "ciência" e "imaginação":

${ }^{2}$ Conventia (conveniência), aemulatio (emulação), analogia e simpatia são as ferramentas epistêmicas, capazes de operar no sentido de identificar e marcar as coisas a partir de semeIhanças, aproximações, duplicações e encadeamentos. Em outras palavras, trata-se de um regime mimético de representação e interpretação do mundo.

3 FOUCAULT, Michel. As palavras e as coisas: uma arqueologia das ciências humanas. Trad. Salma Tannus Muchail. São Paulo: Martins Fontes, 2007, p. 44.

${ }^{4}$ O primeiro ensaio, homônimo ao livro, começa citando Walter Benjamin e o texto de 1933, intitulado "Experiência e pobreza". Nele, o filósofo alemão diagnostica a época moderna como "pobre em experiência", tendo sido a experiência outrora baseada nos vínculos estabelecidos entre integrantes de uma comunidade, como mensagem a ser transmitida, sinônima de sabedoria e autoridade. 


\begin{abstract}
A expropriação da fantasia, que daí decorre, manifesta-se na nova maneira de caracterizar a sua natureza: enquanto ela não era - no passado - algo de "subjetivo", mas era, sobretudo, a coincidência entre subjetivo e objetivo, de interno e externo, de sensível e de inteligível, agora é o seu caráter combinatório e alucinatório, que a antiguidade relegava ao plano de fundo, a emergir em primeiro plano. ${ }^{5}$
\end{abstract}

Atentemos, pois, aos cortes operados entre subjetivo e objetivo, interno e externo, sensível e inteligível. A fundação da ciência moderna e a formulação de seus pressupostos foram possíveis graças ainda a uma outra cisão forçosa, pretendida pelo isolamento de dois momentos da história: o da natureza e o da cultura. Era preciso garantir, por meio de uma narrativa linear, que um tempo de barbárie houvesse acontecido, para que a cultura, a formação do Estado e a hipótese de um contrato-social se assegurassem e justificassem-se como necessários. Concomitantemente a esse processo, deduzimos uma crescente oposição entre o momento de humanização e esta espécie de radical do homem, o animal. A função da imaginação, da fantasia foi entregue às manifestações de alucinação, visão e misticismo, isto é, aos meandros banidos pelo ego cogito, que viria a definir o homem em termos racionais.

Dito isso, e, posteriormente à recapitulação da genealogia da fábula, podemos, de antemão, presumir o diálogo estabelecido entre a poética cinematográfica de Cao Guimarães e esse gênero. Ao se colocar sob a rubrica de uma narrativa que chegou a participar ativamente da construção de um sentido de mundo, imiscuído com a imaginação, o diretor parece querer recuperar certa potência da narrativa, alertando, inclusive, para a proposição de um outro devir, (im)possível, que está em jogo na condição preliminar da fábula. Reconhecido por suas incursões no domínio do documentário, a fabulação do ver proposta por Cao mostra-se apta a afetar-se duplamente, pelo registro documental e pela marca do fantasioso, de forma a garantir efeitos decorrentes dessa dupla exposição.

Ex Isto é uma produção de 2010 e integra o projeto Iconoclássicos, do Itaú Cultural. Como já afirmamos, o filme parte da obra literária experimental Catatau, do escritor curitibano Paulo Leminski, cuja tese é imaginada a partir da seguinte hipótese: "E se René Descartes tivesse vindo para o Brasil com

\footnotetext{
${ }^{5}$ AGAMBEN, Giorgio. Infância e história: destruição da experiência e origem da história. Trad. Henrique Burigo. Belo Horizonte: Editora UFMG, 2012, p. 34.
} 
Maurício de Nassau?". Sabe-se que Nassau foi o enviado pela Companhia Neerlandesa das Índias Ocidentais para gerir as terras por ela conquistada na região nordeste do Brasil. A ideia, portanto, seria testar a pertinência e a extensão do pensamento cartesiano e do raciocínio analítico diante da visceralidade tropical, a partir de uma simples contingência, um evento, uma fantasia capaz de alterar um sistema de pensamento cujas reverberações e sobrevivências permanecem a tornar-nos surdos a certas falas.

A fala da natureza é pura e muda. Mas o homem, outrora, a escutava. Agamben, ainda na obra Infância e história, comenta brevemente a estrutura dos contos de fada ao final do primeiro capítulo do livro, no qual discorre precisamente sobre o homem ser $\mathrm{o}$ animal com a capacidade e não com o imperativo ou com a dádiva da fala, como certo ramo ortodoxo da filosofia enfatizou. O comentário, portanto, refere-se a um estado fabular, no qual os estados de natureza e cultura ainda não encontraram o seu destino:

Por isso, é a fábula, isto é, algo que se pode somente contar, e não o mistério, sobre o qual se deve calar, que contém a verdade da infância como dimensão original do homem. Pois o homem da fábula libera-se do vínculo místico do silêncio transformando-o em encantamento: é um sortilégio, e não a participação em um saber iniciático, que lhe tolhe a palavra. Deste modo, o silêncio místico, sofrido como feitiço, precipita novamente o homem na pura e muda língua da natureza: porém, como encanto, deve ser, rompido e superado. Por esta razão, enquanto o homem, no conto de fadas, emudece, os animais saem da pura língua da natureza e fala. ${ }^{6}$

O que de fato o filme parece pôr em teste é se a natureza, a pura e muda língua da natureza de que fala Agamben, não retorna, não se repotencializa diante de um cenário animado pela flora e pela fauna tropicais. A fábula, portanto, por meio de uma hipótese contingencial, impele a fantasia a desestabilizar um sistema de pensamento, uma rigidez no âmbito da identidade humana e na sua ruptura com o mundo da natureza circundante. Para Descartes, em seu Discurso sobre o método, o animal define-se como máquina, autômato, relação de movimento entre engrenagens, matérias. Isto é, um ser-objeto, disposto em funcionamento.

O personagem Descartes, por uma inversão no filme, é que está exposto como objeto, desafiado a escutar outras linguagens, rumores, timbres. Não a

\footnotetext{
${ }^{6}$ Ibidem, p. 77-78.
} 
partir de uma capacidade nossa, nem graças ao nosso aparato, à orquestração humana, e, porém, técnica, do avistar, mas, de acordo com a própria tomada de posição do animal. Todos se olham. O risco é certo. Em dado momento, em que contracenam Descartes e um papagaio, a voz do personagem humano, em off, começa se indagando, repetindo: “índio pensa?". Mais à frente, a mesma voz confirma: "O papagaio pegou meu pensamento". Raptou uma forma de pensar, contaminou uma estrutura de pensamento.

$$
\text { II - O VER }
$$

O deslocamento cardeal a ser considerado no filme encontra-se nas cenas iniciais. Em contraposição ao cientista como observador, leitor das teorias, consumidor de catataus e tratados, morador das bibliotecas e laboratórios, Descartes, ao chegar a Amazônia, passa a ser o objeto de observação. Visto em um barco por uma câmera que vibra, provoca, bamboleia, chacoalha-se, logo imaginamos a existência por trás da lente. Não há a dependência entre vermos o sujeito por trás da câmera e o reconhecimento de sua existência, de seu olhar. A câmera dá-lhe um modo de ver. Altera-se, assim, a relação estável entre o visível e o sensível, pois sem o vermos, ainda assim, sua presença está assegura.

O olhar detentor perturba aquele que, conforme a sua missão e o seu dom, é quem, supostamente, deveria estar olhando. Essa inversão revela-se central para a construção de uma transformação no pensamento científico daquele que foi o mentor da ideia do homem como senhor de si mesmo, coincidente consigo mesmo. Uno, indivisível, austero.

Mas então, qual seria a força de uma inversão do olhar? Qual a sua potência catalisadora na história do pensamento humano? Sabe-se que o olhar é objeto tradicional de investigação nos campos da biologia, filosofia e historiografia. No entanto, temos no âmbito da história da arte, uma célebre contribuição recente do filósofo e crítico Georges Didi-Huberman para o paradigma do visível, quando permite que sua reflexão detenha-se no reconhecimento não apenas de quem observa, mas no olhar daquele que é observado. Tal pensamento encontra-se na obra $O$ que nós vemos, o que nos olha, verdadeiro tratado sobre as condições do olhar. O primeiro capítulo introduz o que o autor denominará, a partir da obra de James Joyce, de "a inelutável modalidade do visível": 
O que vemos só vale - só vive - em nossos olhos pelo que nos olha. Inelutável porém a cisão que separa dentro de nós o que vemos daquilo que nos olha. Seria preciso assim partir de novo desse paradoxo em que o ato de ver só se manifesta ao abrir-se em dois. ${ }^{7}$

Não há maneira mais profícua e pungente de nos aproximarmos do argumento de Ex isto que a partir desse "abrir-se em dois": eu, observador, possuo um olhar e uma autonomia tal qual aquele que é observado, estabelecendo uma garantia de que esta reversibilidade ou partilha do olhar seja atribuída a quaisquer instâncias, sejam elas humanas ou animais. A imagem, no sentido de visibilidade, é capaz de, por seu sintoma, dilacerar o espectador. Mesmo a forma de um olhar, ainda que o seu conteúdo, o seu sujeito permaneça invisível ou desconhecido. O sintoma é a via por onde aquele que olha corre o risco de abismar-se. E é justamente o abismo o que consome René Descartes. Diante da variabilidade de espécies animais e do reconhecimento desse olhar outro pelo cientista, a cisão aqui já comentada entre racionalidade e irracionalidade torna-se duvidosa e não mais tão clara. Em um processo de assimilação do contorno em que se encontra, Descartes passa a, naturalmente, assemelhar-se aos animais, mimetizando-os, desracionalizando-se, a ponto de, em uma cena específica, manter-se irregularmente sobre as mãos e os pés, cambiante tal qual um trípede ou um quadrúpede.

Aos poucos, o cientista francês parece convencer-se da precariedade do olhar unilateral, que seguramente moveu toda uma episteme, uma ciência e sua série de proposições e descobertas. O homem, no filme, torna-se imagem, cena, cenário. Em um dado momento do filme, o personagem confessa: "Ver é uma fábula", "É para não ver que estou vendo". Pois ver é ver com o corpo, ver com a mão, usar os outros sentidos, menos viciados. Enquanto isso, com uma luneta em mãos, a visão dos pássaros fica subordinada ao recorte que o instrumento impõe. Na obra literária, o trecho a seguir, citado em off na cena do personagem em cima da árvore expõe essa parcialidade do ver:

Ponho mais lentes na luneta, tiro algumas: regulo, aumento a mancha, diminuo, reduzo a marcha, melhoro a marca. $O$ olho cresce lentes sobre coisas, o mundo despreparado para essa aparição do olho, onde passeia não cresce mais luz,

\footnotetext{
${ }^{7}$ DIDI-HUBeRMAN, Georges. O que vemos, o que nos olha. Prefácio de Stéphane Huchet. Trad. Paulo Neves. 2 ed. São Paulo: Ed. 34, 2010, p. 29.
} 
onde faz o deserto chamam paz. Um nome escrito no céu - isolo, contemporizo, alarme na espessura, multiplico explicações, complicando o implícito. ${ }^{8}$

As etapas de observação, formulação de hipótese e confirmação, que constituem o experimento científico analítico, não se autonomizam e recusam-se a funcionar de forma tão prática quanto se pressupõe. Em Catatau, encontramos: "olhar lentes supra o sumo do pensar!" ${ }^{9}$ Cenas do filme criadas a partir da observação de performances animais como o tecer de uma aranha ou de fenômenos naturais como o da pororoca, sugerem que ver, frequentemente, é o mesmo que perder as referências, como Didi-Huberman define. $\mathrm{O}$ homem é tomado pelas águas, o pensamento das águas o inunda, o transborda. $\mathrm{O}$ animal não pode ser mais tão distante e limitado se comparado ao homem. E o homem, por sua vez, não se diferencia pela razão, na medida em que ela não é regular e nem inflexível. Assentado no Brasil como referência para uma generalização, Leminski escreve: "Este mundo é o lugar do desvario, a justa razão aqui delira." ${ }^{10}$

Vale retomar, brevemente, o contexto de participação de Leminski no projeto do concretismo brasileiro. Naquele momento, estava em debate, decerto, estratégias de superação da dicotomia entre sujeito e objeto, sobretudo no que tange à relação entre artista e espectador. Lembremos, pontualmente, a obra "Unidade tripartida" de Max Bill que marcou a primeira Bienal de São Paulo, em 1951 - e influenciou drasticamente o neoconcretismo no Brasil. Apesar de aparentemente longínquo, o paradigma da fita de Moebius permanece como desafio e aceitação da infinitude na finitude da obra, isto é, das transformações contínuas que podem ser constantemente desfeitas. $O$ concretismo e também o neoconcretismo, salvas suas peculiaridades, seriam reações e problematização diante dos pares dentro-fora, subjetificaçãoobjetificação, ativo-passivo, espaço-tempo. Relembremos os versos iniciais da poesia leminskiana "Objeto sujeito": "você nunca vai saber/quanto custa uma saudade/ o peso agudo no peito/ de carregar uma cidade/ pelo lado de dentro/ como fazer de um verso/ um objeto sujeito."11

\footnotetext{
${ }^{8}$ LEMINSKI, Paulo. Catatau: um romance-ideia. São Paulo: Iluminuras, 2013a, p. 18.

${ }^{9}$ Ibidem, p. 20.

${ }^{10}$ Ibidem, p. 19.

${ }^{11}$ LEMINSKI, Paulo. Toda poesia. 1. ed. São Paulo: Companhia das Letras, 2013b, p. 229.
} 


\title{
III - AS IMAGENS
}

Após um período de estadia na Amazônia, o personagem de Descartes viaja para Recife e os momentos que derivam desta experiência colocam em questão a anacronia das imagens. A reflexão instigada no (impossível) encontro do pensamento proeminente com o seu devir só é possível a partir do choque de temporalidades. Há um passado materializado no personagem de René Descartes, suas roupas e seu pensamento exposto em falas ao longo do filme, e há um presente figurado na estética da cidade de Recife, no cenário das feiras atuais em que o personagem passeia, nas manequins multiplicadas pelo comércio, no linguajar dos personagens secundários que o interpelam etc.

Se tomada por uma visão diacrônica tradicional, essa sobreposição de temporalidades distintas seria classificada como pejorativa e não pertinente. Como avaliar um pensamento referente a um tempo e a um lugar passados a partir de parâmetros e conceitos contemporâneos? No entanto, é justamente esta tensão que provoca o abismo no personagem, o estranhamento e a consequente reflexão no espectador. Sobre a utilização desse método anacrônico, por parte do crítico, Didi-Huberman em Diante do tempo defende:

\begin{abstract}
Diante de uma imagem - não importa quão antiga -, o presente não cessa jamais de se reconfigurar, mesmo que o desapossamento do olhar tenha completamente cedido lugar ao hábito enfadado do "especialista". Diante de uma imagem - não importa quão recente, quão contemporânea ela seja -, o passado também não cessa jamais de se reconfigurar, pois esta imagem não se torna pensável senão em uma construção da memória, chegando ao ponto de uma obsessão. ${ }^{12}$
\end{abstract}

Estar diante de uma imagem é, então, estar diante do tempo. A conjunção de variadas temporalidades em Ex isto concebe o trabalho com o tempo um valor em si mesmo. O pesquisador Rafael de Almeida, em artigo sobre o filme, intitulado "Ex isto, de Cao Guimarães e o ultrapassamento de si", relembra fato fundamental que é o de o filme ter sido gerado como uma proposta de criação de um documento sobre artistas e suas obras. ${ }^{13}$ Certamente, para esse

\footnotetext{
${ }^{12}$ DIDI-HUBERMAN, Georges. Diante do tempo: história da arte e anacronismo das imagens. Trad. Alberto Pucheu. 2011.

${ }^{13}$ ALMEIDA, Rafael de. "Ex Isto, de Cao Guimarães, e o ultrapassamento de si". Galaxia, n. 28, p. 274-284, dez. 2014.
} 
convite do Itaú Cultural, havia sido levada em consideração a densa carreira de Cao como documentarista. Mas, como, nesse caso, criar um documento de um personagem remoto, de rotas imaginadas, de mapas perdidos? A escolha é o recurso da mise-en-scène construído entre o ficcional e o documental, entre o passado retido e o futuro propiciado pela obra.

Certamente, Descartes não poderia supor aonde o seu pensamento levaria o homem e que seus preceitos se transformariam em justificativas para atos dos mais pretensiosos. Mas o filme constrói o elo entre os tempos, tornao pensável, imaginável, figurável pela ficcionalização. É a partir desse jogo que percebemos a estranheza, por exemplo, quando assistimos ao personagem caminhar pela feira de frutas e vegetais, observando o funcionamento daquilo que poderíamos denominar, em suas palavras, de máquina-floresta: o animal está submetido às técnicas de limpeza e manuseio, como peça de uma pretensa maquinaria, que se manifesta no momento da pesca, entre a dupla caçacaçador, temível-temente, no sentido de uma integração que extrapola as águas dos rios e permanece na feira urbana. Entretanto, é o encadeamento de tempos distintos, isto é, a montagem, que permite estranharmos e identificarmos a forma de um raciocínio deslocado. O manequim das lojas, se continuássemos a creditar na pertinência da ideia da máquina, é o espectro do homem tornado engrenagem também, pura forma, aparência, aparato - da moda, dos valores comerciais, da reprodução em série.

Tal hesitação de Descartes para com o seu próprio modo de pensar torna instáveis não apenas a atividade de cientista como a sua subjetividade. A mutabilidade do reino animal e vegetal sensibilizam o personagem de Descartes a ponto dele questionar a sua própria identidade. Na obra literária, o autor escreve: "Duvido se existo, quem sou eu se este tamanduá existe?"14 No desenrolar do filme, perdem-se as roupas tão marcadas de uma diferenciação, o cabelo e a barba desgrenham-se, até que o personagem assume uma subjetividade influenciada pelos fatores locais, pela transmutação que atinge toda matéria. A errância da câmera, outrora inoportuna e incômoda, torna-se, progressivamente, íntima, até um dos momentos finais, em que Descartes duela, na praia, com o sujeito detentor do olhar da câmera. O sujeito, antes sugerido como animal, é visto, reconhecido, chamado. Descartes o olha no olho. Nos olha no olhar. Convocado, o sujeito responde com o que constitui a sua

\footnotetext{
${ }^{14}$ LEMINSKI, Paulo. Toda poesia, op. cit. p. 20.
} 
arma: o porte do olhar, o direito a ser sujeito. A responder por si, através do movimento, do golpe, da trama, do truque.

As posições alternam-se. É esta ideia que explica o nome da obra, Ex isto: existir é sempre deixar de ser algo para tornar-se outra coisa que será, futuramente, substituída. A identidade de Descartes com o seu método perde para a subjetividade em devir, posta em movimento pela vivência. Remetendo à máxima cartesiana "penso, logo existo", o pensamento está, a rigor, inevitavelmente entregue às oscilações da existência. O pensar esquiva-se, omite-se na obra - assim como no título do filme de Cao. Torna-se ato, vacila, transfigura-se em imagem, paisagem, onda. Assim como nos pressupostos do concretismo e do neoconcretismo, o externo passa a ser interno, em um movimento similar ao da fita de Moebius, que inverte posições dantes afastadas, opostas.

No âmbito da teoria de Didi-Huberman, a cisão que se descreve no gesto do olhar está presente também no método anacrônico. Distinguem-se duas partes (ou temporalidades) que devem ser confrontadas a fim de revelar novas perspectivas antes escondidas pela unilateralidade do olhar observador ou da análise eucrônica. Por Ex isto tratar-se de uma obra contemporânea, podemos situá-la como exemplo de algumas características próprias às tendências artísticas atuais, que não apenas reproduzem, mas pensam a técnica da montagem. Cada prolongamento e extensão da cena incorre o tempo - da distância, do deslocamento, da antítese - nas imagens. As imagens, diria Didi-Huberman, estão carregadas de tempo. O filósofo aponta um dos efeitos, que poderíamos depreender dessa técnica: "O anacronismo atravessa todas as contemporaneidades. A concordância dos tempos - praticamente - não existe." $^{15}$

$O$ encadeamento de imagens referentes a tempos distintos, no caso de $E x$ isto, corrobora o argumento da produção que se vale das mesmas para sugerir o limite e a precariedade do pensamento científico; a insuficiência de categorias distintivas do homem; a falha de um projeto humano, transparente, eurocêntrico; a reviravolta gerada pelo olhar do olhado, isto é, do objeto, e não apenas do observador em seu estatuto diferenciado; a indeterminação da ciência tendo em vista a variabilidade e vivacidade da natureza, das outras formas de existência, como a dos índios. Que interpelam Descartes,

\footnotetext{
${ }^{15}$ DIDI-HUBERMAN, Georges. Diante do tempo, op. cit.
} 
já no fim da obra, desvelando a nudez que ele, desde o início, sem saber, portava, mas que precisava acontecer. Na nudez final recompõe-se o paradigma de todo conhecimento que se polariza entre o cobrir-se e o descobrir-se, o velar e o desvelar. 